\title{
Aplikasi Metoda Magnetik Untuk Eksplorasi Bijih Besi Studi Kasus : Bukit Munung Kabupaten Bengkayang, Kalimantan Barat
}

\author{
Joko Sampurno*)
}

*) Jurusan Fisika, FMIPA Universitas Tanjungpura

Email : jks_fisika@yahoo.com

\begin{abstract}
Abstrak
Eksplorasi bijih besi telah dilakukan di Bukit Munung Desa Sukabangun Kecamatan Sungai Betung Kabupaten Bengkayang. Tujuan penelitian ini adalah mengidentifikasi sebaran bijih besi di Bukit Munung baik secara lateral maupun vertikal. Penelitian ini menggunakan metode magnetik yang memanfaatkan parameter suseptibilitas batuan untuk menginterpretasikan struktur bawah bumi. Pengolahan data dilakukan dengan metode inversi untuk mendapatkan beberapa parameter fisis struktur bawah permukaan daerah yang ditinjau. Hasil pengamatan geologi dan pemetaan distribusi medan magnet menunjukkan potensi bijih besi berada di sebelah barat laut bukit. Berdasarkan distribusi nilai suseptibilitas batuan pada lintasan $A B$ yang dibuat memotong daerah potensial tersebut, diduga bahwa terdapat tiga lokasi pengendapan batu besi berjenis hematit dan satu lokasi pengendapan batu besi berjenis hematit yang memiliki vein-vein magnetit.
\end{abstract}

Kata Kunci: Bukit Munung, bijih besi, metode magnetik

\begin{abstract}
Exploration of iron ore was carried out at Bukit Munung Desa Sukabangun Kecamatan Sungai Betung Kabupaten Bengkayang. The purpose of this study is to identify the distribution of iron ore at the Bukit Munung both in laterally and vertically. This research applied magnetic method to identify susceptibility of minerals in sub surface. Data processing performed by inversion method to obtain some physical parameters of subsurface structure of the field. The result of the geological observations and mapping of the distribution of magnetic field indicates that the deposits of iron ore are in the northwest of the hill. Based on the distribution of the susceptibility of rocks under line $A B$, that cross the potential areas, can be assumed that there are three locations of the hematite deposition and one location of magnetite veins in hematite deposits.
\end{abstract}

Key words: Bukit Munung, iron ore, magnetic method

\section{Pendahuluan}

Metode geofisika merupakan salah satu metode yang cukup ampuh untuk memetakan sumber daya alam di bawah bumi. Beberapa metode geofisika yang banyak digunakan untuk memetakan sumber daya alam diantaranya metode geolistrik sebagaimana dilakukan oleh Guerin dan Benderitter (1995), metode seismik sebagaimana dilakukan oleh Chen et.al (2004), metode gaya berat sebagaimana dilakukan oleh William (1960), metode self potensial (SP) sebagaimana dilakukan oleh Corwin (1990), dan metode magnetik sebagaimana yang dilakukan oleh Sharma (1987).

Pada penelitian ini akan digunakan metode magnetik untuk memetakan potensi bijih besi di bawah permukaan. Daerah penelitian adalah di kawasan Bukit Munung yang terletak di Desa Sukabangun Kecamatan Sungai Betung Kabupaten Bengkayang tepatnya berada di sekitar titik koordinat $00^{\circ} 51^{\prime} 22,8^{\prime \prime} \mathrm{LU}$ dan 109' 20' 16,2" BT. Lokasi ini dipilih karena secara pengamatan langsung di lapangan terdapat beberapa singkapan berupa batuan besi berwarna hitam kemerahan yang diduga sebagai hematit. 


\section{TOPOGRAFI BUKIT MUNUNG DALAM KOORDINAT UTM 49 N}

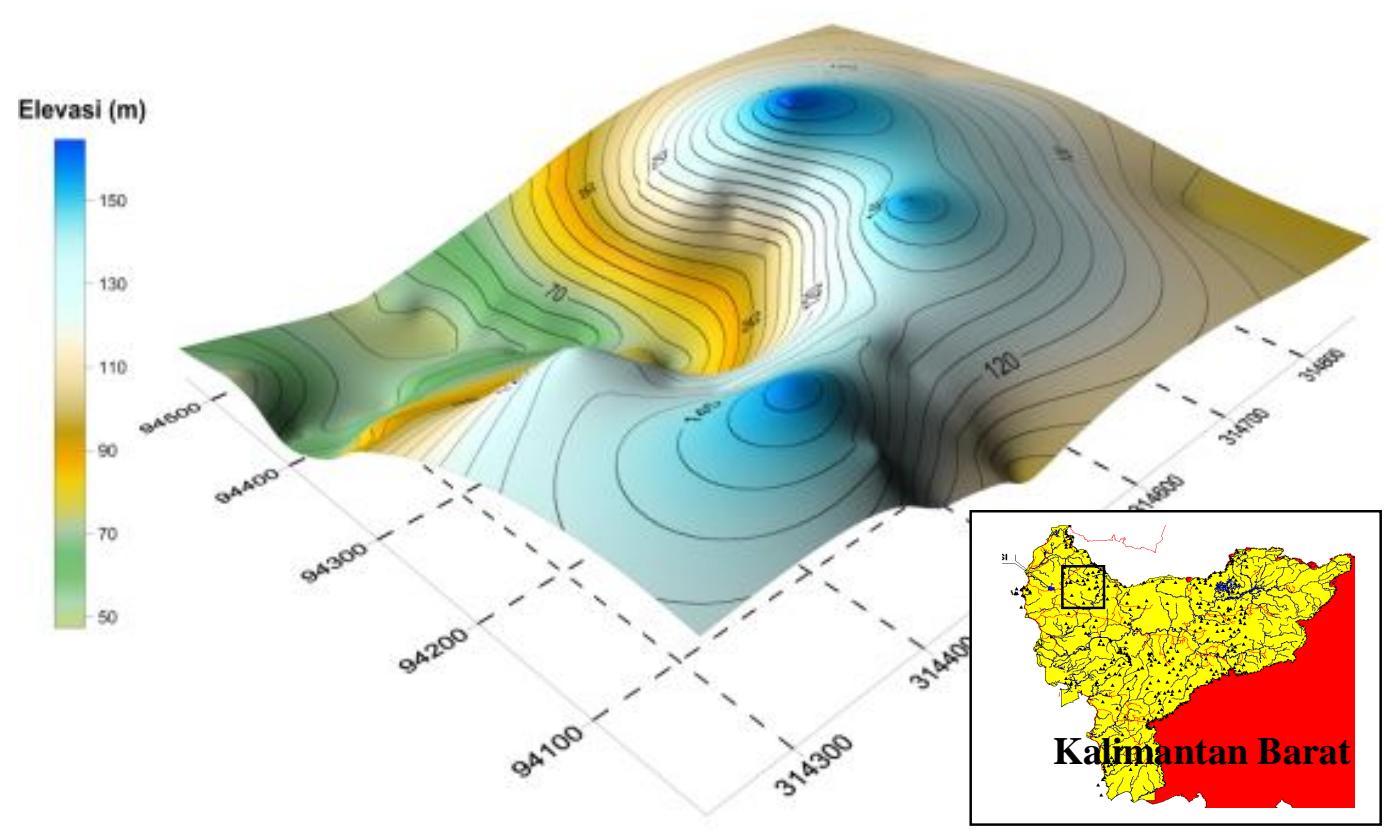

Gambar 1. Letak Lokasi Penelitian dalam peta Kalimantan Barat

Berdasarkan data penelitian yang telah dilakukan oleh N. Suwarna, dkk (1993) diketahui bahwa pembahasan kerangka geologi daerah penyelidikan termasuk dalam lembar Singkawang, Kalimantan, 1316 skala 1 : 250.000 (Gambar 2).

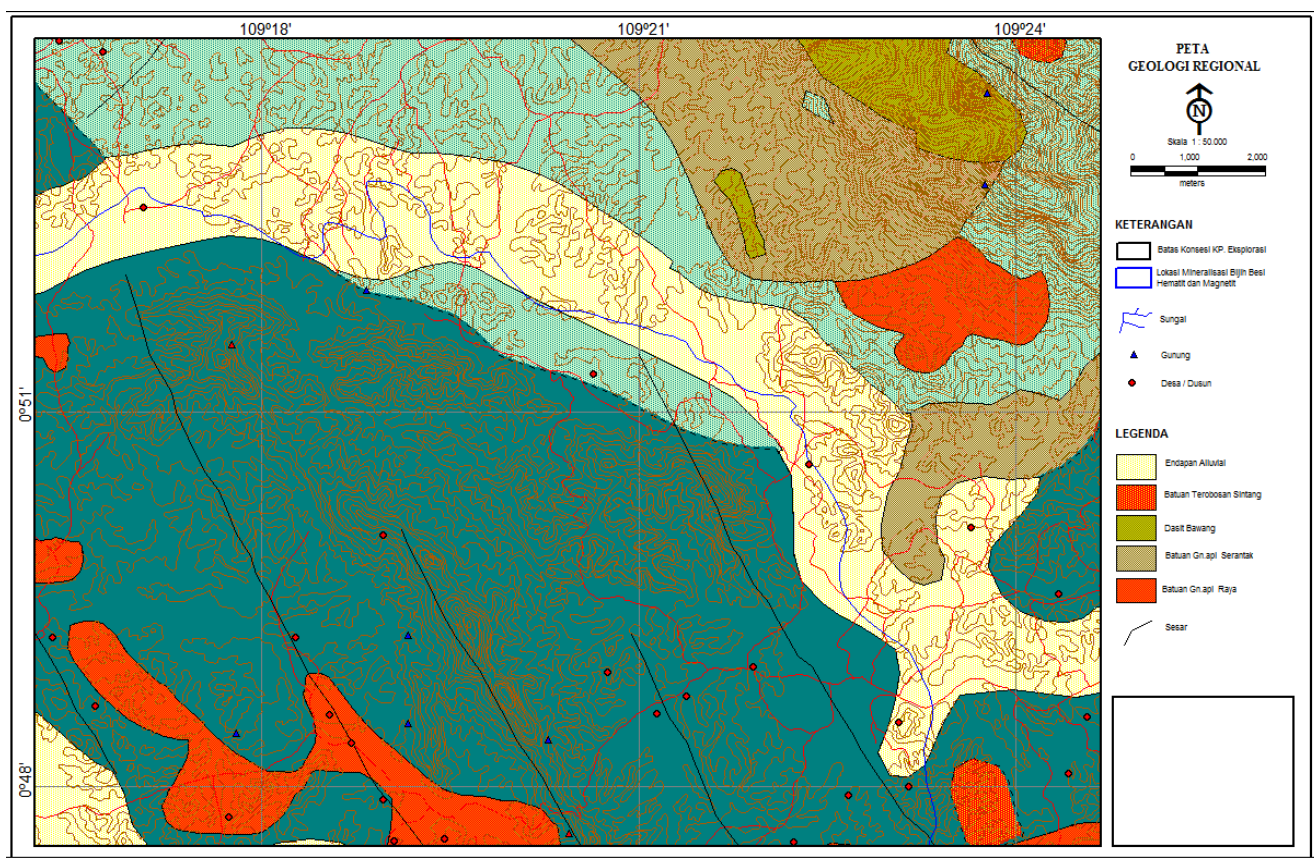

Gambar 2. Peta geologi Kabupaten Bengkayang

(Sumber: Pusat Penelitian dan Pengembangan Geologi Bandung, 1993) 
Kawasan Sungai Betung Kabupaten Bengkayang didominasi oleh satuan batuan dari formasi Sungai Betung dan formasi Banan yang merupakan sedimen yang terbentuk pada jura awal hingga trias akhir (Steve, dkk, 1998). Mineralisasi bijih besi di lokasi ini tersingkap di batas antara kedua formasi tersebut. Mineralisasi bijih besi di lokasi ini diduga terbentuk pada kapur awal bersamaan dengan pembentukan batuan Gunung Api Raya. Struktur patahan atau sesar di daerah ini tidak ada yang berdimensi besar. Patahan-patahan yang ada hanya beberapa patahan kecil yang bersifat lokal, terutama dijumpai di daerah-derah dengan topografi yang tinggi dan terjal.

\section{Metode Geomagnet}

Metode geomagnetik merupakan salah satu metode geofisika yang digunakan untuk survei pendahuluan pada eksplorasi minyak bumi, panas bumi, batuan mineral, maupun untuk keperluan pemantauan (monitoring) gunung berapi. Dasar dari metode magnetik adalah gaya coulomb antara dua kutub magnetik $\mathrm{m}_{1}$ dan $\mathrm{m}_{2}$ (emu) yang berjarak $\mathrm{r}(\mathrm{cm})$ dalam bentuk (Telford,dkk., 1979):

$$
F=\frac{m_{1} m_{2}}{\mu_{0} r^{2}} r \quad \text { (dyne) }
$$

dengan $\mu_{0}$ adalah permeabilitas medium dalam ruang hampa, tidak berdimensi dan berharga satu.

Kuat medan magnet $(\mathrm{H})$ pada suatu titik yang berjarak $\mathrm{r}$ dari $\mathrm{m}_{1}$ didefinisikan sebagai gaya perstuan kuat kutub magnet, dapat dituliskan sebagai (Telford,dkk., 1979):

$H=\frac{F}{m_{2}}=\frac{m_{1}}{\mu_{0} r^{2}} r$

Bila dua buah kutub magnet yang berlawanan mempunyai kuat kutub magnet $+p$ dan $-p$, keduanya terletak dalam jarak l, maka momen magnetik $\mathrm{M}$ dapat ditulis sebagai (Telford,dkk., 1979):

$$
M=p l r_{1}=M r_{1}
$$

dengan $\mathrm{M}$ adalah vektor dalam arah unit vektor $r_{1}$ dari kutub negatif ke kutub positif.

Benda magnet dapat dipandang sebagai sekumpulan dari sejumlah momen-momen magnetik. Bila benda magnetik tersebut diletakkan dalam medan luar, benda tersebut menjadi termagnetisasi karena induksi. Oleh karena itu, intensitas kemagnetan I adalah tingkat kemampuan menyearahnya momen-momen magnetik dalam medan magnet luar, atau didefinisikan sebagai momen magnet persatuan volume (Burger, dkk, 2006) :

$I=M / V$

Tingkat suatu benda magnetik untuk mampu dimagnetisasi ditentukan oleh suseptibilitas kemagnetan atau $\mathrm{k}$, yang dituliskan sebagai (Burger, dkk, 2006) :

$I=k H$

Besaran yang tidak berdimensi ini merupakan parameter dasar yang dipergunakan dalam metode magnetik. Harga $\mathrm{k}$ pada batuan semakin besar apabila dalam batuan tersebut semakin banyak dijumpai mineral-mineral yang bersifat magnetik.

Bila benda magnetik diletakkan dalam medan magent luar $\mathrm{H}$, kutub-kutub internalnya akan menyearahkan diri dengan $\mathrm{H}$ dan terbentuk suatu medan magnet baru yang besarnya adalah (Telford,dkk., 1979):

$$
H^{\prime}=4 p k H
$$

Medan magnet totalnya disebut dengan induksi magnet B dan dituliskan sebagai (Telford,dkk., 1979) :

$$
B=m_{r} H
$$

dengan $m_{r}=1+4 p k$ dan disebut sebagai permeabilitas relatif dari suatu benda magnetik. Satuan B dalam emu adalah 
gauss, sedangkan dalam geofisika eksplorasi dipakai satuan gamma (g) dengan $1 \mathrm{~g}=10^{-5}$ gauss $=1 \mathrm{nT}$.

Pada metode geomagnet variasi medan magnetik yang terukur di permukaan merupakan target dari survey magnetik (anomali magnetik). Besarnya anomali magnetik berkisar ratusan sampai dengan ribuan nano-tesla, tetapi ada juga yang lebih besar dari $100.000 \mathrm{nT}$ yang berupa endapan magnetik. Secara garis besar anomali ini disebabkan oleh medan magnetik remanen dan medan magnet induksi. Medan magnet remanen mempunyai peranan yang besar pada magnetisasi batuan yaitu pada besar dan arah medan magnetnya serta sangat rumit diamati karena berkaitan dengan peristiwa kemagnetan yang dialami sebelumnya. Sisa kemagnetan ini disebut dengan Normal Residual Magnetism yang merupakan akibat dari magnetisasi medan utama.

Anomali yang diperoleh dari survey merupakan hasil gabungan dari keduanya. Bila arah medan magnet remanen sama dengan arah medan magnet induksi maka anomalinya bertambah besar, demikian pula sebaliknya. Dalam survey magnetik, efek medan remanen akan diabaikan apabila anomali medan magnet kurang dari $25 \%$ medan magnet utama bumi. Adanya anomali magnetik menyebabkan perubahan dalam medan magnet total bumi dan dapat dituliskan sebagai (Telford,dkk., 1979) :

$$
H_{T}=H_{M}+H_{A}
$$

dengan :

$H_{T}=$ medan magnetik total bumi

$H_{M}=$ medan magnetik utama bumi

$H_{A}=$ medan anomali magnetik

Bila besar $H_{A} \ll H_{T}$ dan arah $H_{A}$ hampir sama dengan arah $H_{T}$ maka anomali magnetik totalnya adalah (Telford,dkk., 1979):

$\Delta T=H_{T}-H_{M}$

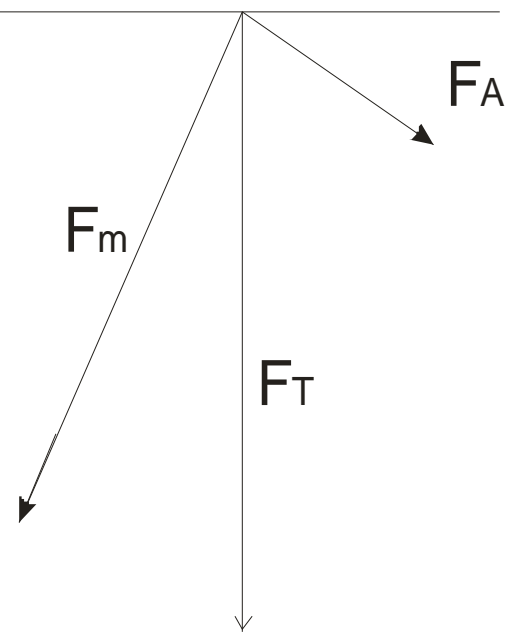

Gambar 3. Vektor yang menggambarkan medan anomali $\left(\mathrm{F}_{\mathrm{A}}\right)$, medan utama $\left(\mathrm{F}_{\mathrm{M}}\right)$ dan medan magnet total $\left(\mathrm{F}_{\mathrm{T}}\right)$ (Robinson dan Coruh, 1988)

\section{Metodologi}

Penelitian ini dilakukan dengan tahapan-tahapan: studi pustaka, pemodelan sintesis, akuisisi data, pengolahan data dan interpretasi. Studi pustaka meliputi studi geologi daerah penelitian baik secara regional maupun lokal. Pemodelan sintetik dilakukan untuk mengestimasi respon anomali magnetik di daerah penelitian dengan mengadopsi besaran-besaran yang diketahui dari studi pustaka. Respon anomali benda magnetik perlu dimodelkan karena respon anomali ini tidak hanya bergantung pada batuan bawah permukaan saja tetapi dipengaruhi oleh deklinasi, inklinasi dan intensitas magnetik suatu daerah.

Rangkaian penelitian digambarkan pada Gambar 4 di bawah ini. Proses akuisisi data menggunakan 2 magnetometer, satu berperan sebagai base yang berfungsi sebagai pengukur variasi harian medan total magnet di base station. sementara satu alat lagi berperan sebagai roover magnetometer yang berfungsi untuk mengukur total medan magnet di setiap station pengukuran. Medan magnetik observasi (Tobs) diukur pada setiap stasiun yang tersebar di area penelitian. Medan magnet IGRF adalah nilai refferensi medan magnet di suatu tempat. Medan magnet IGRF merupakan nilai kuat medan magnetik ideal di suatu tempat di permukaan bumi tanpa adanya 
pengaruh anomali magnetik batuan. Variasi medan magnet harian disebut koreksi harian (diurnal correction) diukur di base station. Secara umum anomali magnetik suatu tempat dapat dirumuskan sebagai :

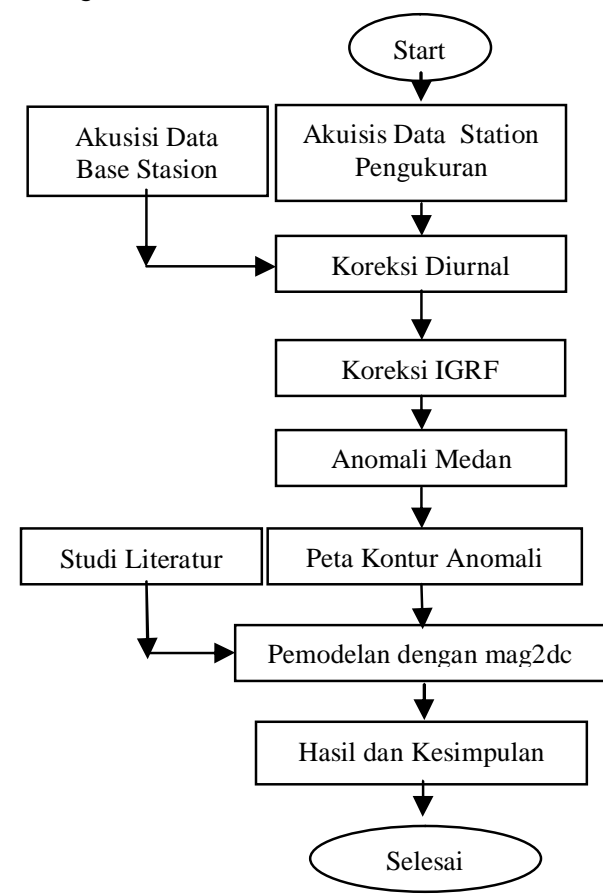

Gambar 4. diagram alir penelitian

\section{Hasil dan Diskusi}

Hasil pengamatan geologi di daerah penelitian menunjukan adanya singkapan-singkapan batu besi berjenis hematit di beberapa titik.

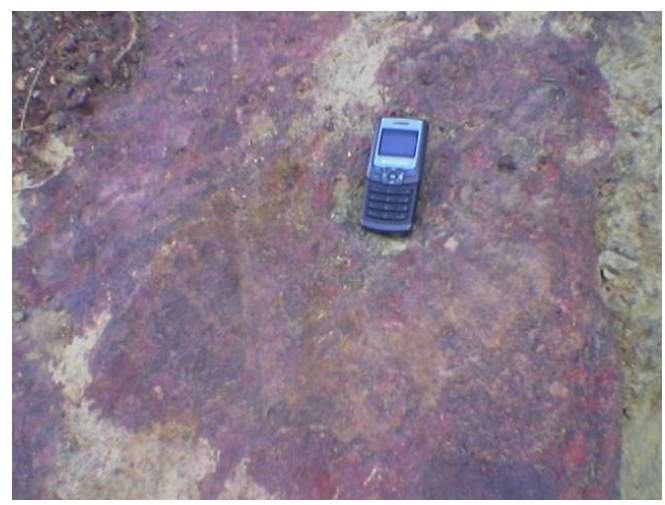

Gambar 5. Bijih besi (iron ore) yang diduga sebagai hematit di lembah bukit Munung
Singkapan yang ditemukan di daerah penelitian menunjukkan sifat sebagai bijih besi dengan kemagnetan kuat (Gambar 5). Dari hasil pengamatan lapangan, ukuran dari bijih yang ada di daerah Bukit Munung dapat dibedakan menjadi dua tipe yaitu: Sebagai bolder yang terlepas dan singkapan di lerenglereng bukit.

Hasil pemetaan secara mapping daerah penelitian menghasilkan distribusi intensitas medan magnet yang telah dikoreksi sebagaimana ditampilkan pada Gambar 6. 


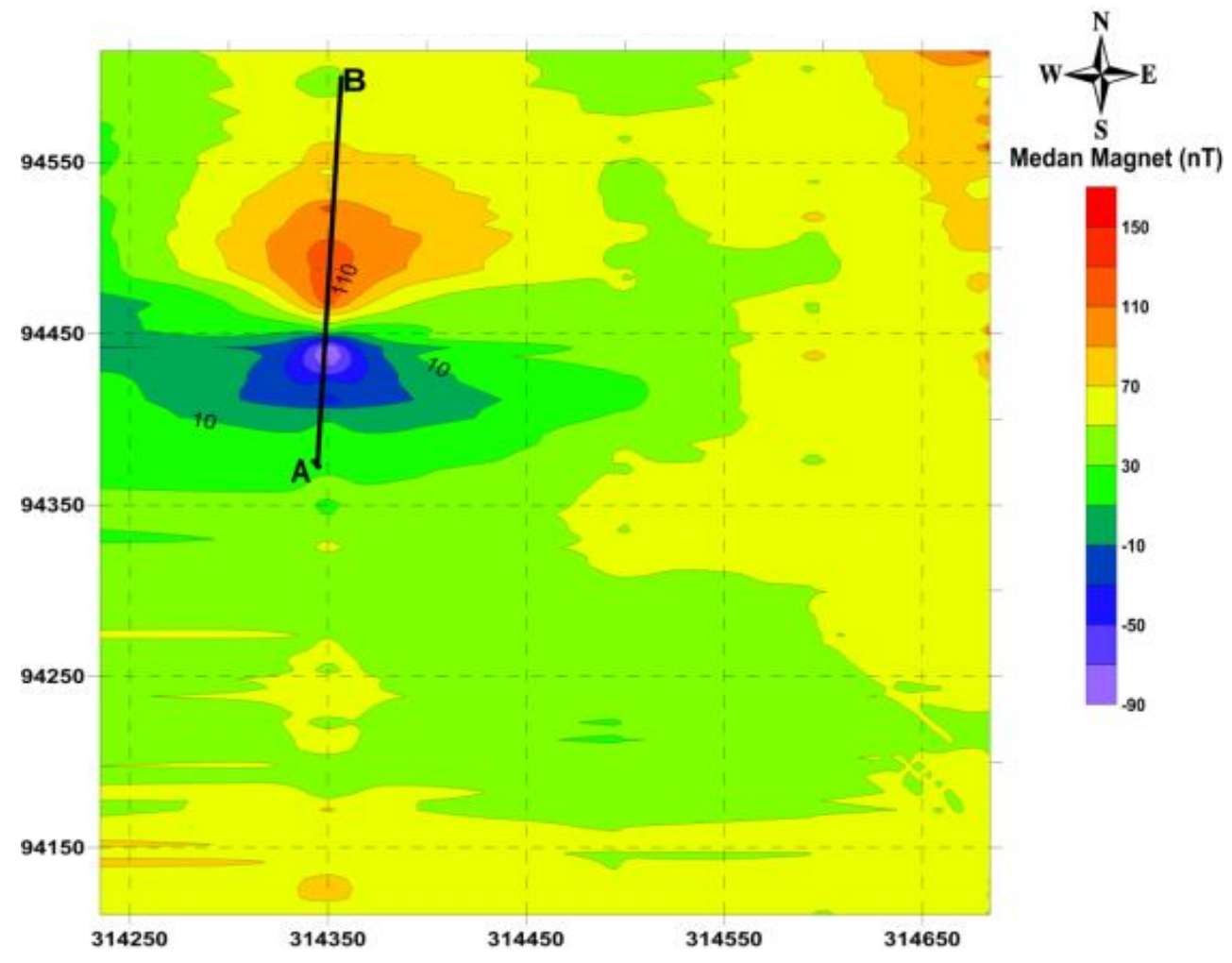

Gambar 6. Distribusi intensitas medan magnet dalam koordinat UTM $49 \mathrm{~N}$ dan posisi lintasan $\mathrm{AB}$

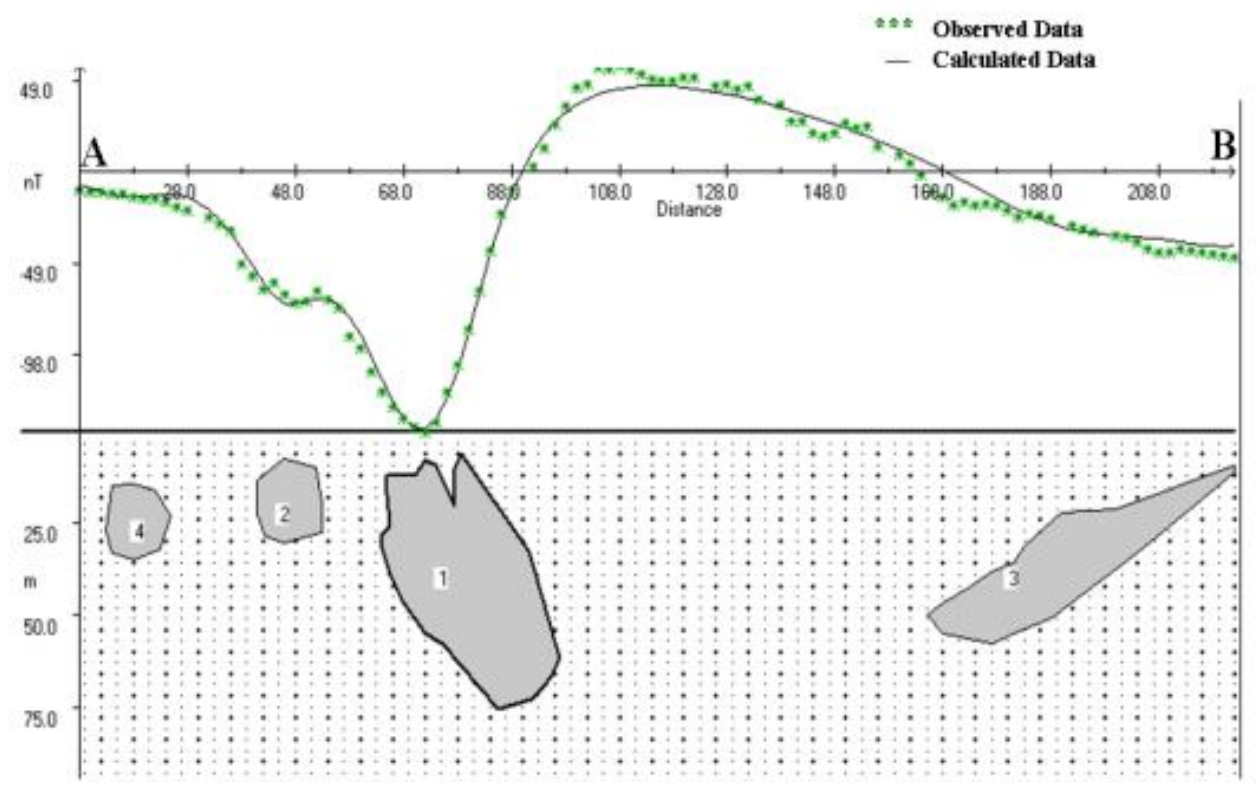

Gambar 7. Interpretasi penampang vertikal pada lintasan $A B$ 
Dari Gambar 7. dapat diinterpretasikan bahwa terdapat empat buah batu besi yang berada di sepanjang lintasan AB. Batu besi pertama berbentuk border memiliki nilai suseptibilitas 0.22 SI berada pada posisi $64 \mathrm{~m}$ hingga $97 \mathrm{~m}$ dari posisi awal lintasan (titik A) dan kedalaman $6.13 \mathrm{~m}$ hingga $75.78 \mathrm{~m}$ dari permukaan. Berdasarkan nilai suseptibilitasnya maka dapat diduga bahwa pada batuan tersebut berjenis hematit yang memiliki vein-vein magnetit.

Batu besi yang kedua berbentuk border memiliki nilai suseptibilitas 0.12 SI berada pada posisi $41 \mathrm{~m}$ hingga $53 \mathrm{~m}$ dari posisi awal lintasan dan kedalaman $7.46 \mathrm{~m}$ hingga $30.46 \mathrm{~m}$ dari permukaan. Berdasarkan nilai suseptibilitasnya maka dapat diduga bahwa batuan tersebut berjenis hematit.

Batu besi ketiga menyerupai vein memiliki nilai suseptibilitas 0.15 SI berada pada posisi $165 \mathrm{~m}$ hingga $248 \mathrm{~m}$ dari posisi awal lintasan dan kedalaman $8.99 \mathrm{~m}$ hingga $58 \mathrm{~m}$ dari permukaan. Berdasarkan nilai suseptibilitasnya maka dapat diduga bahwa batuan tersebut berjenis hematit.

Batu besi keempat berbentuk border memiliki nilai suseptibilitas 0.01 SI berada pada posisi $13 \mathrm{~m}$ hingga $25 \mathrm{~m}$ dari posisi awal lintasan dan kedalaman $14 \mathrm{~m}$ hingga $35 \mathrm{~m}$ dari permukaan. Berdasarkan nilai suseptibilitasnya maka dapat diduga bahwa batuan tersebut berjenis hematit.

\section{Kesimpulan}

Hasil pengamatan geologi dan pemetaan distribusi medan magnet menunjukkan keberadaan potensi bijih besi di sebelah barat laut bukit. Berdasarkan distribusi nilai suseptibilitas batuan di daerah potensial tersebut diduga terdapat tiga lokasi pengendapan batu besi berjenis hematit dan satu lokasi pengendapan batu besi berjenis hematit yang memiliki vein-vein magnetit.

\section{Pustaka}

Burger, H.R.,Sheehan, Anne F., Jones, Craig H., 2006, Introduction to Apllied Geophysiscs, W.W. Norton \& Company, New York
Corwin, R.F., 1990, The self-potential method for environmental and engineering applications, in Ward, S.W.,Geotechnical and environmental geophysics, v.I: p. 127-145.

Chen, G., Liang, G., Xu, D., Zeng, Q., Fu, S., Wei, $X_{\text {., }} \mathrm{He}, \mathrm{Z}$., and $\mathrm{Fu}, \mathrm{G}$., Application of a shallow seismic reflection method to the exploration of a gold deposit, J. Geophys. Eng. 1 (2004) 12-16, DOI: 10.1088/17422132/ 1/ 1/ 002

Guerin, Roger, and Benderitter, Yves, 1995, Shallow karst exploration using MT-VLF and DC resistivity methods: Geophysical Prospecting, v. 43, no. 5, p. 635-654.

Hinze, William J., Application of the gravity method to iron ore exploration, Economic Geology, May 1960, v. 55, p. 465-484

Moss, Steve J., Carter, A., Baker, S., And Hurford, A.J., (1998), A Late Oligocene Tectono-Volcanic Event In East Kalimantan And The Implications For Tectonics And Sedimentation In Borneo, Journal of The Geological Society, 155, 177192.

Robinson, E.S. dan C. Coruh. 1988. Basic Exploration Geophysics. J. Willey \& Sons, New York

Sharma, P.V., Magnetic method applied to mineral exploration, Ore Geology Reviews, Volume 2, Issue 4, August 1987, Pages 323-357, ISSN 01691368

Suwarna N., Sutrisno, de Keyser F., Langford R.P., Trail D.S. (1993), Peta Geologi lembar Singkawang, Kalimantan, 1:250 000

Telford, W.N., Geldard, L.P., Sherrif, R.E., and Keys, D.A., 1979, Applied Geophysics, Cambridge University Press, Cambridge, London,Newyork, Melbourne. 